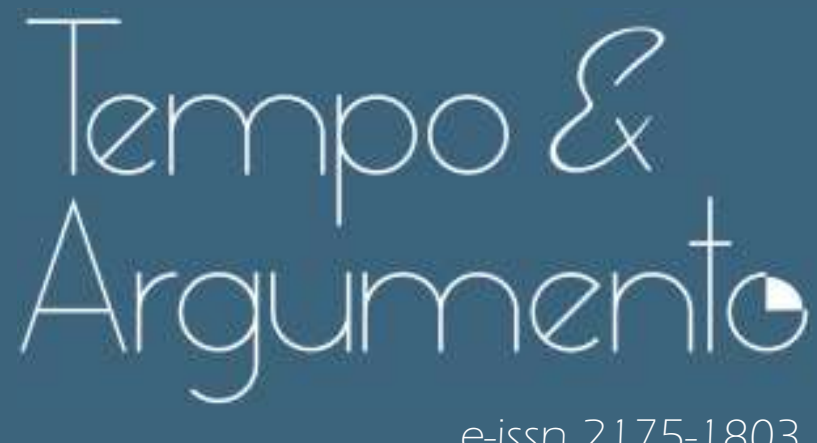

e-issn 2175-1803

\title{
As narrativas e alternativas de análise sobre o contexto da luta de libertação em África: caso Amílcar Cabral
}

- Arnaldo Sucuma

Doutor em Serviço Social pela Universidade Federal de Pernambuco (UFPE).

Professor Substituto na Universidade de Pernambuco (UPE). Professor e coordenador do Núcleo de Estudos e Pesquisa em Direitos Humanos, Relações Étnico-Raciais e Meio Ambiente do Centro Universitário - Patos (UNIFIP). Pesquisador associado ao Núcleo de Estudos Afro-Brasileiros da Universidade Federal de Pernambuco (UFPE). Patos, PB - BRASIL lattes.cnpq.br/6749265583090174 arnaldoarsu@gmail.com

(D) orcid.org/0000-0001-8790-8369

Para citar este artigo:

SUCUMA, Arnaldo. As narrativas e alternativas de análise sobre o contexto da luta de libertação em África: caso Amílcar Cabral. Tempo e Argumento, Florianópolis, v. 13, n. 34, e0103, set./dez. 2021.

dof http://dx.doi.org/10.5965/2175180313342021e0103

Recebido: 21/06/2021 Aprovado: 08/09/2021 


\title{
As narrativas e alternativas de análise sobre o contexto da luta de libertação em África: caso Amílcar Cabral
}

\begin{abstract}
Resumo
Este texto tem como objetivo refletir sobre as narrativas e as análises alternativas referentes ao contexto de luta de libertação nacional na Guiné-Bissau, que inclui um breve relato da colonização europeia em África. O trabalho se enquadra no campo da história e sociologia política, procura abordar os processos de resistências na Guiné Portuguesa, nome atribuído à atual Guiné-Bissau no período da colonização lusitana, assim como procurou-se trazer uma análise sobre as relações políticas costuradas no período da colonização em torno de unidade étnica e identidade nacional. Para realizar esta reflexão, levou se em consideração a perspectiva panafricanista de Amilcar Cabral. O trabalho tem como referencial teórico o pensamento pós-colonial, aplicado aos processos políticos dos países africanos, centrado numa perspectiva de um estudo essencialmente bibliográfico. 0 pensamento de Amílcar Cabral ajudou a conduzir esta análise, visto que ele foi o líder do partido que conseguiu conquistar a hegemonia política para conduzir a luta pela independência, chancelada pelos diversos grupos étnicos, associações de bairros e outros grupos de resistência formada pela elite urbana que era formada por funcionários públicos de grandes casas comerciais na administração portuguesa.
\end{abstract}

Palavras-chave: luta de libertação nacional; resistências étnicas; identidade guineense; colonialismo.

\section{Narratives and Alternatives for the analysis of the context of the liberation struggle in Africa: Amilcar Cabral case}

\begin{abstract}
This text aims to reflect on the narratives and alternative analysis regarding the context of the national liberation struggle in Guinea-Bissau, including a brief history of European colonization in Africa. The work fits into the field of history and political sociology, seeking to address the process of resistance in Portuguese Guinea, the name given to present-day Guinea-Bissau during the period of Portuguese colonialization. It also tries to analyze the political relations sewn in the colonization period built around ethnic unity and national identity in order to face Portuguese colonialization. To carry out this reflection, it was considered the Pan-Africanist perspective of Amilcar Cabral. The theoretical framework is the post-colonial thought, applied to the political processes of African countries, centered on the perspective of an essentially bibliographical study. Amilcar Cabral's concept helped to conduct this analysis, as he was the leader of the party that managed to conquer political hegemony to lead the struggle for independence, endorsed by the various ethnic groups, neighborhood associations and other resistance groups formed by the urban elite and civil servants from large commercial enterprises in the Portuguese administration.
\end{abstract}

Keywords: national liberation struggle; ethnic resistance; Guinean identity; colonialism. 


\section{Introdução}

O presente trabalho é resultado de análise crítica realizada a partir de uma pesquisa bibliográfica sobre o contexto da luta de libertação nacional na GuinéBissau. O estudo possui uma grande relevância acadêmica e política, visto que traz uma reflexão sobre o processo de resistência e de luta pela independência na Guiné-Bissau, com suas especificidades. O problema principal deste trabalho consiste em refletir sobre as narrativas e alternativas referentes à luta de libertação nacional na Guiné-Bissau. Neste sentido, o nosso objeto de trabalho está centrado na análise do contexto da luta de libertação nacional na GuinéBissau, considerando as suas peculiaridades. O artigo tem como objetivo analisar as narrativas e possibilidades adotadas pelas lideranças políticas locais enquanto estratégia para traçar caminhos adequados para promover a luta de libertação nacional. Em termos metodológicos, trata-se de uma pesquisa de natureza qualitativa, em que a coleta de informações foi realizada mediante a seleção de livros e artigos científicos. Foram utilizadas também fontes primárias e secundárias em termos bibliográficos (ECO, 1984, p. 65).

Em termos teóricos, o estudo está ancorado nos autores, que desenvolvem estudos referentes ao processo de movimentos de resistência ao jugo colonial, bem como a reconstrução política dos países africanos após a conquista de suas independências políticas, especialmente no caso da GuinéBissau.

O processo de resistência às injustiças, racismo, torturas perpetradas pela administração colonial na Guiné vem sendo estudado por diversos autores guineenses, entre os quais Cabral (1974), Lopes (1999; 2011), Cardoso (2008), Gomes (2010), e outros intelectuais como M`Bokolo (2009) Kohl (2011), Hampaté Bâ (2010), Wick (2005). Os autores supracitados demonstram a importância de compreender o processo de resistência nas lutas de libertação nacional para enfrentar o jugo colonial.

Cabe salientar que a região que hoje se chama de Guiné-Bissau, nem sempre foi o mesmo território da chamada Costa da Guiné ou Africana, ou, Senegâmbia. Esta divisão feita pela colonização europeia, que traçou as

\footnotetext{
* Nesse texto optou-se por manter a grafia da língua nativa.
} 
fronteiras, resultou na separação dos povos da região, sem levar em conta as tradições culturais dos grupos étnicos, gerando problemas até aos dias atuais (GOMES, 2010).

No período do tráfico de populações africanas como escravos, Guiné, Guinauha ou Gnawa, era o termo usado para designar "terras de pretos", que é uma palavra de origem berbesca, Guinéus, que significava negro (LEMOS, 1996).

Portanto, a ideia central do texto consiste em refletir sobre o processo de narrativas de resistências à administração colonial portuguesa, a partir da luta de libertação nacional na Guiné-Bissau, liderada por Amilcar Cabral.

O texto está estruturado em três partes: a primeira trata das experiências políticas de lutas de libertação em África. A segunda traz a reflexão referente ao contexto da luta de libertação nacional na Guiné-Bissau. Na terceira parte o debate está centrado em torno da reflexão contemporânea sobre alternativas de luta da libertação nacional e unidade nacional.

\section{Breve contextualização das experiências de lutas de libertação em África}

O processo colonial que aconteceu no continente africano foi muito intenso e prejudicial para os povos africanos de diversos territórios e culturas. Foi um processo que interferiu no contexto político e cultural de todas as regiões da África.

Durante o período colonial, os cidadãos negros e mestiços nativos da Guiné não tinham os mesmos direitos que os cidadãos brancos portugueses que viviam na Guiné Portuguesa. Por outro lado, os mestiços tinham mais aceitação política do que os negros não mestiços. Segundo Gomes (2010), a discriminação dos negros era um fato observado na época, enquanto que os mestiços tinham algumas regalias.

Alguns países africanos conquistaram suas independências por vias de negociação política e outros por vias de luta armada. Todas as colónias portuguesas tiveram de enveredar pela opção da luta armada, diante da resistência do colono. O contrário aconteceu na larga maioria das colónias 
britânicas e francesas. Por exemplo, Senegal, que é um país vizinho, que faz fronteira com a Guiné-Bissau, conseguiu sua independência mediante uma transferência de poder da França, em 1960, formando uma federação com o Mali. Entretanto, a guerra que a França combateu na Argélia influenciou diretamente o processo de negociação da independência do Senegal. Isso ajuda explicar um dos principais motivos que permitiu o Senegal conquistar a independência por via de uma negociação política e pacífica

Após a conquista de independência de diferentes territórios colonizados pela França houve um processo de acúmulo de aprendizados e de conhecimentos, de ponto de vista político e abriu portas para futuras relações econômicas entre a França e suas ex-colônias (BARTHÉLÉMY, 2010).

No caso da Guiné-Bissau, o processo de luta pela independência foi diferente do Senegal. Porque, Portugal não quis negociar a independência de suas ex-colônias. Amílcar Cabral tentou promover negociações políticas com administração colonial para discutir a independência da Guiné-Bissau. Mas não teve sucesso.

Ao longo da luta de independência, Cabral mantinha diálogo com diversos líderes africanos de diversos países como Sékou Touré de Guiné Conacri, Léopold Sédar Senghor do Senegal, Kwame Nkruma do Gana, entre outros. Este movimento de Cabral visava construir estratégias de enfrentamento ao jugo colonial que assolava o continente e também procurar apoio desses líderes na luta pela independência da Guiné-Bissau.

Por isso mesmo que o movimento fundado pelo Amilcar Cabral estava inserido dentro de uma perspectiva pan-africanista que era muito forte naquela época (FOBAJONG, 2011; LOPES, 2011; MATEUS, 1999).

Amílcar Lopes Cabral, na qualidade do líder da independentista da GuinéBissau e Cabo Verde teve que viajar para diversos países na África, com intuito de somar força no âmbito do combate ao jugo imperial nos territórios colonizados. Uma das críticas que ele fazia era de que a luta pela independência em África precisava ser acompanhada por um processo de elaboração teórica. Porque, para Cabral, era perceptível uma certa ausência de ideologia, fato que 
pode ter ligação com desconhecimento das realidades africanas, bem como a falta de interesse em construir um projeto próprio e a importação de métodos estrangeiros para o continente africano. Do Amílcar Cabral:

Só poderemos transformar verdadeiramente a nossa própria realidade com base no seu conhecimento concreto e nos nossos esforços e sacrifícios próprios. Vale a pena lembrar neste ambiente tricontinental, onde as experiências abundam e os exemplos não escasseiam, que, por maior que seja a similitude dos casos em presença e a identificação dos nossos inimigos, infelizmente ou felizmente, a libertação nacional e a revolução social não são mercadorias de exportação. (CABRAL, 1978, p. 73)

A reflexão crítica que Amílcar Cabral fazia aos movimentos de luta pela independência na África, se insere numa contribuição teórica que ele tentava trazer para o debate, em um ambiente de combate ao jugo colonial. Para Cabral:

A deficiência ideológica, para não dizer a falta total de ideologia, por parte dos movimentos de libertação nacional - que tem a sua justificação de base na ignorância da realidade histórica que esses movimentos pretendem transformar, constituem uma das maiores senão a maior fraqueza da nossa luta contra o imperialismo. (CABRAL, 1978, p. 73)

As reflexões acima revelam que Cabral acompanhava de perto as experiências de lutas pela independência em outros territórios em África, assim como procurava dar suas opiniões sobre os vários movimentos anticoloniais em África, tendo a caraterística de ser um dos pouquíssimos líderes africanos (e provavelmente o único da África lusófona) a conhecer diretamente a questão fundiária, não pertencendo às elites urbanizadas (BUSSOTTI, 2020).

\section{O contexto da luta da libertação nacional na Guiné-Bissau}

A Guiné-Bissau é um país multicultural e multiétnico. De acordo com o censo de 2009, o país tem atualmente 14 etnias, mais uma pequena parte da população que não pertence a nenhuma etnia', que corresponde a $2.2 \%$ da população (MINISTÉRIO DA ECONOMIA, DO PLANO E DA INTEGRAÇÃO REGIONAL, 2009, p. 22).

\footnotetext{
Entende-se por etnia como a unidade de um grupo que compartilha o pertencimento da mesma cultura, território, valores e tradição.
} 
A Guiné-Bissau sofreu muito com os impactos negativos da colonização, sobretudo no aspecto cultural, com a desvalorização das culturas étnicas locais para assumir a cultura ocidental como símbolo de civilização. Os nomes tradicionais de pessoas foram substituídos pelos nomes ocidentais. Cada nome tradicional tem um significado ligado à cultura local e à ancestralidade, portanto tem uma relevância fundamental na vida das comunidades. Vice-versa, para a colonização, as culturas e a história dos povos africanos não se enquadravam em uma cultura civilizada (GOMES, 2010).

Durante o período da colonização, Portugal não desenvolveu políticas públicas que contribuíssem para o desenvolvimento da sua antiga colônia que era chamada da "Guiné-Portuguesa". Segundo Djú:

Os portugueses cientes de que mais cedo ou mais tarde serão expulsos devido as resistências que enfrentavam e as guerras travadas contra os pequenos estados, reinos em diferentes cantos da "Guiné-Portuguesa" resolveram não criar as condições propícias para o desenvolvimento, começando desde a limitação de acesso à escola aos povos locais. (DJú, 2019, p. 5)

Portanto, a falta de acesso às políticas públicas constitui um dos aspectos que ajudou a gerar uma insatisfação da população local, reforçando assim a unidade em torno da luta pela independência, sob a liderança de Amílcar Cabral.

Amílcar Lopes da Costa Cabral - nasceu na República da Guiné-Bissau, concretamente na cidade de Bafatá (região leste do país), a 12 de setembro de 1924, filho de emigrantes cabo-verdianos. O pai, Juvenal Antônio Lopes da Costa Cabral, nasceu na ilha de Santiago em 1889, filho de Antônio Lopes da Costa, um abastado proprietário rural, e de Rufina Lopes Cabral, filha de agricultores (pequenos proprietários). Com apenas oito anos, Juvenal foi enviado para Portugal, para estudar - um luxo só possível a uma reduzidíssima elite das ilhas. Foi o primeiro aluno negro a entrar nos portões da escola primaria de Santiago de Cassurães, na Beira Alta. Seguiu-se o Seminário de Viseu, onde segundo ele mesmo, passou os melhores anos da sua vida. Mas, diante das dificuldades da família em manter os seus estudos, devido à estiagem, Juvenal retornou a Cabo Verde em 1906. Ao retornar a Cabo Verde, os pais destinaram-no ao sacerdócio católico, mas ele já adulto, em vez de concluir o curso no Seminário de São 
Nicolau, preferiu instalar-se na itha de Santiago. Em abril de 1911, viajou para a Guiné-Bissau, à procura de emprego, de futuro, de melhor sorte. Ali viverá mais de trinta anos. Funcionário público em Bolama, foi, depois, o primeiro professor de uma escola primária em Cacine (no sul do país), com uma escassa meia dúzia de alunos. Ele mesmo se definirá, um dia, como «um obscuro professor não diplomado» (DUARTE SILVA, 2008, p. 6).

Em 1932, aos oito anos de idade, Amílcar seguiu o pai no regresso a Cabo Verde. Foram morar na ilha de Santiago numa zona rural, com a madrasta e os meios irmãos. Dois anos depois, em 1934, Iva Évora também regressa a Cabo Verde e se encarrega da educação do filho. Amílcar já tinha dez anos, e não tinha ainda frequentado ensino primário. Assim, começou a estudar em 1936, aos doze anos de idade. Em um ano concluiu os estudos primários, e teve que mudar para a ilha de São Vicente junto com a mãe para dar continuidade aos estudos no Liceu Gil Eanes. Foi Iva que com um grande esforço material, apoiou Cabral no que ele mesmo chamou de "infância agreste" e na educação escolar (DUARTE SILVA, 2008, p. 10).

De acordo com Dalila Cabrita (1999) foi a falta de universidades nos territórios dominados por Portugal no continente africano, mais precisamente Angola, Cabo-Verde, Guiné-Bissau, Moçambique e São Tomé e Príncipe, que forçou os jovens destes referidos territórios a deslocarem-se a Portugal para obterem uma formação superior. Mas podemos perceber que isso também se deve a uma política adotada pelo governo colonial português, que consistia em limitar o acesso ao ensino nos territórios colonizados ao mínimo intelectual, ou seja, ao ensino prático de algumas atividades.

Ao longo de seus estudos em Portugal ele construiu relações políticas com companheiros da Guiné-Bissau, Cabo Verde, Angola e Moçambique. Portanto, foi justamente nesse período que Amílcar Cabral junto com seus companheiros da Guiné-Bissau e Cabo Verde com começaram a desenhar estratégias políticas para conquistar a independência política. Este contexto demonstra a importância que a Casa dos Estudantes do Império teve na vida pessoal e política de Cabral, que abriu as portas para que ele pudesse construir um diálogo com seus colegas 
de Moçambique como Eduardo Mondlane, Agostinho Neto e Mário Pinto de Andrade de Angola, Aristides Pereira de Cabo Verde, etc.

O final da década de 1950 foi marcado pelo nascimento de movimentos de luta pela independência nas colônias portuguesas em África.

Nessa altura foram criadas as primeiras organizações com caráter partidário, a exemplo do MLGC (Movimento de Libertação da Guiné e Caboverde). Depois seguia a UPG (União de Povos da Guiné fundada pelo caboverdiano Henri Labery), o RDAG (Reunião Democrática Africana da Guiné), a UNGP (União dos Naturais da Guiné Portuguesa), a UPLG (União da População Libertada da Guiné), que agrupava a minoria de etnia Fula do Senegal, e o MLG (Movimento de Libertação da Guiné fundada em 1958) que agregava a maioria da etnia manjaca da Guiné, o MING (Movimento para a Independência da Guiné, fundada em 1954 criado por José Francisco e Luís António da Silva, “Tchalobé”), PAI (Partido Africano para Independência, que mais tarde daria origem ao PAIGC fundada em 1956, já por iniciativa de Amílcar Cabral, e os seus compatriotas cabo-verdianos e guineenses: Luís Cabral, Aristides Pereira, Elisée Turpin, Abílio Duarte, Júlio de Almeida e Fernando Fortes), e por fim FLING (Frente de Libertação Nacional da Guiné fundada em 1962) dirigida por Labery, Pinto Bull e François Kankola Mendy, que seria resultante da unidade partidária entre o UPG, o RDAG e a UPLG (MONTEIRO, 2017).

Entre todos os movimentos supracitados, o PAIGC foi o que conseguiu catalisar maior hegemonia política para dirigir a luta de libertação nacional, em torno de um programa denominado de "consciência nacional" para combater o colonialismo. Além do apoio de diversos grupos étnicos, o PAIGC contava também com outros grupos de resistência da elite urbana que era formada por funcionários públicos na administração portuguesa e associações de bairros etc. Esses fizeram várias reivindicações como estratégia política para negociar a independência total junto a administração portuguesa. Segundo Monteiro:

Grupo formado pelas elites urbanas coube a responsabilidade de culminar com a luta armada de libertação nacional em 1963. Tais grupos eram caracterizados em forma de associações de bairro, clubes desportivos, dirigidos pelos assimilados e intelectuais que eram funcionários das grandes casas comerciais coloniais (Casa 
Gouveia, Banco Ultramarino entre outros) que reivindicavam dos seus patrões ações contra o racismo e a discriminação racial no serviço público colonial, o trabalho forçado, más condições de trabalho, salários baixos, a falta de educação para os nativos e o reconhecimento e liberdade para os povos da Guiné. (MONTEIRO, 2017, p. 234-235).

Portanto, não se pode sustentar que o movimento de luta pela independência da Guiné-Bissau e Cabo Verde não procurou vias de negociação política e diplomático para obter a independência política. Uma das formas de resistência que foi usada pelos sindicatos de trabalhadores portuários e comerciais ligados ao PAIGC foi representada pelas greves, que tinham objetivo de forçar uma negociação com administração portuguesa. Porém, o governo colonial não quis negociar nem com os sindicatos e nem com a lideranças de PAIGC.

Em 1956, aconteceu a fundação do PAIGC (Partido Africano para a Independência da Guiné e Cabo-Verde), que iniciou a luta armada em 1963. Em Angola, uma das colônias mais importante para Portugal, deu início à revolta armada em 1961. O governo português temia que acontecesse um colapso da sua economia, que dependia largamente das colônias africanas. De acordo com Sendo Almeida (1981),

O governo [...] procurou neutralizar a ação revolucionária com a adoção de medidas que minorassem o descontentamento nos territórios colonizados [...]. A tentativa de integrar os africanos aos objetivos portugueses, substituindo a discriminação aberta pela intensificação da "assimilação", caracteriza a nova orientação para as colônias. Suas primeiras consequências são a abolição do Estatuto Indígena e a reforma do ensino primário. (ALMEIDA, 1981, p. 41)

Apesar das reformas no setor do ensino que estavam acontecendo nas colônias, Portugal decidiu desencadear uma guerra contra os movimentos de libertação como na Guiné-Bissau, Moçambique e Angola.

Considerando o momento delicado que PAIGC iria enfrentar no âmbito da luta pela independência, Amílcar Cabral começou a construir discurso alinhado em torno da unidade nacional, dentro de uma perspectiva que valoriza a diversidade étnica. Segundo Semedo (2012) a criação do PAIGC em 1956 está 
baseada na luta pelo acesso à liberdade, direitos, justiça e desenvolvimento. Neste sentido, o partido foi fundado dentro da perspectiva de unidade, liberdade e desenvolvimento. No manifesto, que simbolizou os princípios e as estratégias do PAIGC, Amílcar Cabral defendia a seguinte ideia:

Os princípios básicos do nosso partido é a unidade e luta [...] qualquer que sejam as diferenças que existem, é preciso ser um só, um conjunto, para realizar um dado objetivo. Cada um pode conservar a sua personalidade, as suas ideias, a sua religião, os seus problemas pessoais para obedecer a todos a uma coisa, agir em conjunto contra qualquer adversário. Não é preciso unir toda gente para lutar num país, basta realizar um certo grau de unidade. Tomadas em conjunto, unidade e luta significa que para lutar é preciso unidade, mas para ter unidade também é preciso lutar. (CABRAL; COMITINI, 1978, p. 120)

O discurso de Cabral teve seus efeitos no período da mobilização pela luta armada e política, junto aos combatentes e a um pequeno grupo da elite política da época; uma boa parte desta elite era mestiça e formada por funcionários públicos da administração colonial. Isso demonstra o resultado do discurso da unidade interétnica e política proferido pelo líder de PAIGC. Segundo Kohl (2011, p. 39), o "movimento independentista advogou um modelo de unidade nacional na diversidade étnica”.

No que se refere à organização territorial, o PAIGC queria a Constituição de uma Câmara de Representantes na Guiné-Bissau e em Cabo Verde, que juntos iriam "estudar e decidir sobre as possibilidades, as bases e a forma de realizar, no quadro da unidade africana, a união orgânica dos povos da Guiné e Cabo Verde, com fundamento nos laços de sangue e nos laços históricos que ligam esses povos" (DUARTE SILVA, 2008, p. 75).

De acordo com os Estatutos do PAIGC, o território da Guiné-Bissau estava dividido e 11 regiões e 28 zonas, no entanto, atualmente o país está organizado 8 regiões, mais o sector autônomo de Bissau, e Cabo-Verde era dividido em 2 regiões e 9 zonas.

As zonas eram formadas por secções organizadas pelo PAIGC, e tinha como organismo superior a conferência de zona, que realizava duas reuniões 
anuais para a escolha de delegados, discussão de assuntos relacionados com a zona e eleger o comitê da referida zona.

Neste sentido, as regiões eram constituídas por duas zonas, e contavam com um órgão superior, conhecido como a Conferência regional, que organizava reuniões semestrais, com a missão de discutir as questões relacionadas com as respectivas regiões, e eleger os delegados para o congresso.

Uma das estratégias implementadas pelo PAIGC foi a inclusão do órgão do poder tradicional, e dos chefes tradicionais étnicos, no seu sistema de organização, o que nos faz perceber uma clara abertura do Partido junto às estruturas tradicionais étnicas. Esta estratégia do PAIGC, além de integrar ao Partido os diversos grupos étnicos que serviam de elo de ligação entre o povo e a luta de libertação, tinha como objetivo fazer renascer elementos positivos das sociedades tradicionais, dentro desta nova sociedade idealizada pelo Engenheiro Amílcar Cabral. Assim através do Partido, Amílcar Cabral, abriu espaço para a participação de diferentes grupos étnicos através de seus representantes, assim como tinha também a representação de grupos que representavam os setores da população que viviam na zona urbana. Portanto, as instituições tradicionais étnicas tiveram uma atenção especial, considerando que elas exercem até os dias atuais uma grande influência, sobre as populações que representam.

Assim, o PAIGC conseguiu ter a maior penetração junto aos chefes tradicionais do que outros movimentos de libertação, que não conseguiram atingir essa parcela da população.

O surgimento dos movimentos de luta da libertação nacional, que tinham uma ação armada e diplomática, fez com que Portugal, nas décadas de 1960 e 1970, através do seu governo colonial implementasse reformas em diversas áreas. O objetivo primário era evitar qualquer sanção por parte da comunidade internacional, procurando desmentir as denúncias dos movimentos independentistas sobre a violência contra direitos humanos que o regime colonial português praticava nas suas colônias.

Portanto, no território hoje chamado Guiné-Bissau, a educação, antes da colonização europeia, era e continua sendo a tradição oral africana, que acontece 
por meio de ritos de iniciação e pela transmissão de símbolos que sustentam a produção de significados (HAMPATÉ BÂ., 2010, p. 181-218).

Trata-se de um modelo de educação valorizado pelas comunidades que a praticam, considerando o seu valor na transmissão de conhecimento de geração em geração.

Além do momento dos ritos de iniciação, a transmissão de conhecimentos é feita também de diversas formas, podendo acontecer ao ar livre, à noite, em volta da fogueira, nas reuniões com os mais velhos ou sábios, que podem contar muitas histórias dos tempos dos seus antepassados. Essas histórias não estão escritas, são narradas. Por isso mesmo, existe um ditado que diz: "na África, quando um velho morre é uma biblioteca que desaparece" (HAMPATÉ BÂ, 2010).

No entanto, a educação no período pré-colonial transmitida oralmente, como diz Cá (2008), carrega um dinamismo vital, comunica-se e prolonga-se até chegar ao indivíduo e ao grupo, cumprindo, assim, uma importante função sociocultural, pois no pensamento negro africano, a tradição oral é o laço que une os vivos aos antepassados. Os colonizadores pretendiam acabar com as formas de transmissão dos conhecimentos das populações autóctones e incutir nas suas mentes a cultura dita "civilizada", obrigando-as a abandonar as suas culturas. Mas apesar dessa repressão, as culturas tradicionais africanas resistiram ao período colonial e sua estratégia de repressão, tendo sido praticadas na clandestinidade, nos espaços distanciados daqueles ocupados pelos colonizadores. Até hoje na Guiné-Bissau essa forma de educação está ainda presente no cotidiano da grande parte da população, especialmente nas zonas rurais do país.

Além da questão cultural e educacional, outro aspecto importante que também está entre as causas do início da luta armada foi a grande hostilidade de trabalho forçado, torturas, opressão e racismo que colonização portuguesa praticou contra a população na Guiné-Bissau. Segundo Monteiro:

Apesar de todas as resistências organizadas por grupos étnicos, a violência dos portugueses foi ganhando maiores proporções. Os colonialistas portugueses aliaram a ocupação não só à repressão como também o racismo, a perseguição das crenças, a tortura, 
massacres, mortes, recursos utilizados como forma de intimidar os nativos no que refere os levantes e a resistência contra a imposição colonial. Essas revoltas dos povos nativos não só exprimiram de um lado o ódio do povo em relação à dominação portuguesa no tocante a recusa total de pagamentos excessivos de impostos e da soberania portuguesa, como também por outro forjou a conscientização da unidade para luta de libertação nacional. (MONTEIRO, 2017, p. 232)

Nos finais do século XIX e início do século XX, a cidade de Bissau estava organizada de forma hierarquizada entre os letrados, conhecidos por civilizados e os que os portugueses chamavam de indígenas, conhecidos como grupos que não tinham uma aproximação com a língua e cultura dos portugueses e que não eram cristãos. Segundo Cardoso:

Em termos de estratificação social, a Guiné colonial da segunda metade do século XIX caracterizava-se por linhas de clivagem em volta de várias camadas sociais, entre as quais se destacavam os mulatos (descendentes de um europeu e de uma africana) e os mestiços (de mãe guineense e de pai cabo-verdiano). Estes grupos preferiam em geral a cultura europeia e o cristianismo. Muitos oriundos de Cabo Verde ocupavam o topo da pirâmide e formavam o núcleo dos designados por creoulos, outra expressão para designar os descendentes do cruzamento de europeus e africanos ou de qualquer outra mestiçagem baseada em origens socioculturais diversas. A seguir vinham os africanos cristãos ou gurmetos, de pura ascendência africana. O denominador comum que os unia era o facto de todos reclamarem a africanidade, uma identidade social contraposta à identidade social europeia. (CARDOSO, 2008, p. 8)

Durante a administração portuguesa, em 1959 houve greve dos trabalhadores do porto de Pinjiquiti, que reivindicavam melhores condições de trabalho, de salário e de diálogo com o governo colonial. O governo respondeu aos trabalhadores com atos de hostilidades, atirando com arma de fogo, que resultou na morte de muitos trabalhadores. O ato é conhecido como massacre de Pinjiquiti.

Os acontecimentos em 1959 no porto de Bissau, conhecido como massacre de Pindjiguiti e as fracassadas possibilidades de estabelecimento do diálogo com o governo colonial por parte do PAIGC, contribuíram para desmontar todo o esforço diplomático que vinha sendo feito por parte do PAIGC, no sentido de promover uma luta pacífica pela independência. Os acontecimentos do 
Pindjiguiti geraram em Bissau um clima de tensão e de perseguição por parte da Polícia Internacional de Defesa do Estado-Direção Geral de Segurança (PIDEDGS) contra os jovens que supostamente estavam envolvidas na reivindicação subversiva. A reivindicação foi reprimida pelo governo, e com medo da repressão, dias depois começou a se registar as primeiras fugas de jovens com destino ao país irmão e vizinho da Guiné Conacri. Eles partilhavam um sentimento comum de insatisfação com o regime colonial, embora, em certos casos, as suas opções de engajamento na revolução podiam não coincidir, cada um procurava o grupo com o qual se identificava ideologicamente, mas o PAIGC devido ao prestígio e influência do Amílcar Cabral era o movimento que acabou por se impor, atraindo a maior parte dos jovens (SEMEDO, 2012).

Portanto, o massacre de Pinjiquiti constitui a causa imediata que desencadeou a luta armada pela independência de Guiné-Bissau e Cabo Verde que encerrou em 24 de setembro de 1973, com a proclamação unilateral de heróis nacionais e combatentes da liberdade da pátria. Um ano depois, concretamente no dia 24 de setembro de 1974, Portugal reconheceu a independência da Guiné-Bissau.

\section{Debate contemporâneo sobre alternativas de luta da libertação nacional e unidade nacional}

Diante das condições acima expostas, as lideranças do PAIGC foram forçadas a aderirem a luta armada como forma de impor a legitimidade de conquistar independência e a soberania dos povos da Guiné-Bissau e Cabo Verde. Portanto, esta luta armada iniciou em 1963, nas zonas rurais do sul e norte do país, depois se estendeu para todo território nacional.

Nesta perspectiva específica de unidade para luta de independência, a identidade é uma construção que se elabora em uma relação que opõe um grupo aos outros grupos com os quais mantém contato (BARTH, 1969 apud CUCHE, 2002, p. 182).

Cabe salientar que não concordamos com a visão Barth, ao entender a identidade étnica como aleatório o caráter marcador da diferença entre grupos 
étnicos. Porém, a contribuição de Barth é importante para o caso Guiné-Bissau, porque sua visão é política, fato importante para analisar as relações estabelecidas entre diferentes grupos envolvidos no processo de descolonização, assim como, a relação de poder que foi estabelecida no âmbito político-estatal depois da independência. Portanto, não se tratava de grupos isolados no interior do país, mas sim de grandes grupos envolvidos nas relações sociais e políticas na guerra de independência e na defesa de seus interesses na construção do Estado nacional.

Portanto, graças à unidade nacional que envolve os grupos étnicos ao lado do PAIGC, o país conquistou a sua liberdade política, que foi oficializada no dia 24 de setembro de 1973, uma data que marca o nascimento do Estado da GuinéBissau, com a proclamação da independência em Madina de Boé, na zona leste do país. Em 10 de setembro de 1974, Portugal reconheceu o país como independente. Consumada a etapa da proclamação da independência, os guineenses revolucionários ligados ao PAIGC, que eram operários de baixo escalão no período colonial (estivadores, eletricistas carpinteiros/marceneiros, pedreiros, como também os desempregados e os camponeses) e os "intelectuais revolucionários" também do PAIGC - compostos por algumas personalidades cabo- verdianas e/ou seus descendentes (assimilados cuja maioria trabalhava antes como funcionário no governo colonial) - tiveram que sair das zonas libertadas para assumir o poder na capital Bissau. Havia uma regra clara dentro do partido: só podia ocupar função no governo quem tivesse participado da luta armada. Com isso, os cargos governamentais foram distribuídos pelos dirigentes do partido e pelas pessoas mais destacadas na luta. Apesar de alguns combatentes revolucionários, sobretudo da ala guineense, não tinha qualificação necessária para tais funções (LOPES, 1999).

Segundo Carlos Lopes, com a entrada dos combatentes em Bissau, impunha-se a criação de novas relações de poder, pois era preciso contar com uma nova lógica e uma nova entidade: o Estado com sua racionalidade intrínseca (LOPES, 1999, p. 20).

A vitória da luta de independência aconteceu graças à ideia de unidade nacional. O princípio da unidade constitui uma alternativa singular e indispensável 
dentro das ações de Amílcar Cabral. Nos encontros do partido, ao tentar explicar a força que representa a união, Cabral pegou um palito de fósforo e o quebrou; em seguida, pegou todos da caixinha e, ao tentar quebrar, não conseguiu. Com isso, Cabral tentava explicar a força que a unidade representa. Não obstante, essa unidade, não significava que tinha que acontecer da mesma forma, com as mesmas visões e comportamentos. Segundo VAMBE, Amílcar Cabral (2011, p. 49) entendia que a gente do povo luta junto, mas com visões diferentes. Nesta ordem de ideia, Cabral explicava que se as coisas não forem diferentes não é preciso fazer unidade:

Quer dizer no nosso princípio unidade é no sentido dinâmico de movimento. Cada um pode conservar sua personalidade, suas ideias, sua religião, seus problemas pessoais, um pouco de sua maneira de jogar mesmo, mas eles têm que obedecer a uma coisa, tem que agir em conjunto para meter golos contra qualquer adversário com que estivera a jogar, quer dizer: a roda desse objetivo concreto meter o máximo de gols contra o adversário, o fundamento principal da unidade é que para ter unidade é preciso ter coisas diferentes, se não forem diferentes não é preciso fazer unidade não a problema de unidade. (CABRAL, 2013, p. 4)

Portanto, não tem como compreender a visão da Unidade em Cabral sem revisitar o seu princípio político sobre o pan-africanismo. Conforme afirma Franco (2009, p. 138), é necessário considerar que a unidade no pensamento de Cabral possui três dimensões: unidade na Guiné; unidade da Guiné e Cabo-Verde; unidade dos movimentos pela independência das possessões africanas contra o colonialismo português na conquista de apoios de movimentos, partidos e organizações de âmbito internacional. Portanto, a unidade africana está sempre presente nas falas de Amílcar Cabral. Conforme Alexis WICK:

Uma das razões principais que militam a favor da revolução e da unidade africana é o caráter artificial das fronteiras coloniais e o fato de que o sentimento indenitário, não correspondendo a essas fronteiras, as ultrapassa grandemente. Assim, a unidade africana permite acentuar as semelhanças entre as populações abrangidas, em vez de destacar as suas diferenças (por mais reais que sejam), e, em consequência, facilita a elaboração coletiva de estratégias de revolta contra as cadeias de opressão comum. (WICK, 2005, p. 80)

Considerando o movimento pan-africanista, antes de ver as identidades regionais e étnicas, e sem ao mesmo tempo ignorá-las, Cabral considerava a 
identidade dos povos africanos como um princípio de unidade, e procurou se engajar na construção da solidariedade entre os povos do continente. Segundo Wick (2011, p. 78), Amílcar Cabral reconhece a contradição e não evoca, de forma específica, os critérios identitários que definem o seu projeto nacional. Não obstante, segundo WICK, Cabral:

[...] afirma que a submissão a uma mesma dominação colonialista e racista fornece uma base comum aos diferentes povos da Guiné e de toda a África. A confrontação com o racismo da administração colonial confere aos diferentes grupos que formam a sociedade guineense a consciência de pertencer a uma identidade africana. [...] o colonialismo cria um sentimento que ultrapassa outras identidades locais, sem, contudo, as eliminar. Isso está implícito na sua insistência no binacionalismo, baseado no objetivo da unidade da Guiné e das Ithas de Cabo-Verde. (WICK, 2005, p. 79)

Neste sentido, o pensamento de Cabral não colocava uma hegemonização nacional dos diferentes povos e suas culturas; ele buscou sempre combater as divergências étnicas defendendo uma identidade além da origem de cada povo. Cabral (2014, p. 33) afirmava que, [...] aqui não há nem manjaco, nem papel, nem mandinga, nem balanta, nem fula, nem sussu, nem biafada, nem filho de caboverdiano. Aqui há filhos da Guiné e Cabo-Verde que querem lutar pelo Povo. De acordo com os interpretes de Cabral, afirma Wick,

[...] releva a caracterização negativa do tribalismo e geralmente positiva de etnicidade. Tribalismo para Cabral é a articulação política de uma organização social "racialista". Ela faz corresponder uma instituição política a um dado grupo social e definido por critérios identitários preestabelecidos e fixos. Ela reenvia à expressão política exclusivista o sentimento identitário que representa a "etnicidade". Para Cabral, já o valor positivo da etnicidade inscreve-se no quadro da sua importância, na perseverança das populações. [...] a sua ligação às manifestações identitárias locais (e portanto, à etnicidade), é ideológica, política e ética, mas é sobretudo realista. (WICK, 2005, p. 370)

Portanto, para Amílcar Cabral, a base da unidade estava em cada origem étnica se perceber pertencente a uma ancestralidade em comum, neste sentido, o divisionismo étnico só interessava a administração colonial, que, numa constante campanha do colonialismo em favor do tribalismo, reforçava as distinções na tentativa de sabotar a unidade do movimento. Segundo MENDY: 
Cabral possuía uma mentalidade aberta invulgar que the permitia ver para além da confusão e da mistificação de raça e de cor, de ou classe e etnia, da "missão de civilização" portuguesa culturalmente arrogante e racista e da política paternalista de assimilação - as justificações subtis e as inteligências tácticas de "dividir e governar" utilizadas por Portugal para camuflar os objectivos e as realidades coloniais. (MENDY, 2005, p. 771)

Considerando o debate acima, o projeto de luta pela independência do PAIGC não se delimitava as fronteiras nacionais, era um movimento binacional de luta anticolonial e antiracial, que, antes de guineense e cabo-verdiano, por isso, criou-se o Partido Africano para a independência da Guiné e de Cabo-Verde. Segundo Carlos Lopes (2011, p. 10), no pensamento de Cabral, o processo de realização do potencial africano só será possível a partir de um processo contínuo de revolução estrutural e social dos diferentes países, capaz de levar os povos, unificados, "à arena da participação ativa".

\section{Considerações Finais}

A colonização europeia causou uma série de conflitos entre as populações locais, práticas de racismo e violência em todos os territórios colonizados no continente africano.

A luta pela independência da Guiné tem como elemento básico promover a soberania, liberdade, autonomia e dignidade das etnias que compõem o povo da Guiné-Bissau.

A colonização portuguesa na Guiné, para consolidar o seu projeto de poder e controle do território usou a estratégia de promover conflitos entre a população local, criou uma hierarquização social, oferecendo privilégios para determinados grupos, considerados assimilados, dificultando assim o processo de construção de unidade nacional para promover a luta pela independência.

Apesar dessa estratégia política nefasta da colonização portuguesa, o projeto da construção de estado nacional na Guiné-Bissau seguiu seu curso, sob Liderança de Amílcar Cabral, que comandou a Luta de libertação nacional, dentro da perspectiva de promover a unidade entre a Guiné-Bissau e Cabo-Verde, para conquistar independência política. 
A resistência, unidade nacional diálogo foram caminhos importantes que ajudaram no enfrentamento ao jugo colonial e na conquista pela independência. Portanto, a luta armada foi a consequência da falta de diálogo e negociação que a administração portuguesa não queria estabelecer com as lideranças do PAIGC, que clamavam pela independência política.

\section{Referências}

BARTHÉLÉMY, Pascale. L'enseignement dans l'Empire colonial français: une vieille histoire. Revista Histoire de l'éducation, [France], n. 128, p. 5-27, oct./déc. 2010.

BUSSOTTI, Luca. Políticas agrícolas e usurpação de terras em Moçambique Independente: resistências, movimentos sociais, papel do Estado. Cadernos de Estudos Africanos, Lisboa, n. 40, p. 37-62, 2020. Disponível em:

https://journals.openedition.org/cea/5243?lang=en. Acesso: 09 out. 2021.

CÁ, Lourenço Ocuni. A constituição da política do currículo na Guiné-Bissau e o mundo globalizado. Cuiabá: EdUFMT, 2008.

CABRAL, Amílcar. A prática revolucionária: unidade e luta. Praia: Fundação Amílcar Cabral, 2013. v. 2.

CABRAL, Amilcar. Guiné-Bissau, nação africana forjada na luta. Lisboa: Publicações Nova Aurora, 1974.

CABRAL, Amílcar. Pensar para agir melhor: intervenções no seminário de Quadros, 1969. Cabo Verde: Fundação Amílcar Cabral, 2014.

CABRAL, Amílcar. Unidade e luta I: a arma da teoria. Lisboa: Seara Nova, 1978.

CABRAL, Amilcar; COMITINI, Carlos. A arma da teoria. 2. ed. Lisboa: Seabra Nova, 1978.

CARDOSO, Carlos. Sociedade civil, espaço público e gestão de conflitos: o caso da Guiné-Bissau. Yaoundé: [s.n.], 2008.

CUCHE, Denys. A noção de cultura nas ciências sociais. Bauru: EDUSC, 2002.

DJú, Edgar. Estado guineense e o desenvolvimento nacional. São Luis: [s.n.], 2019. 
DUARTE SILVA, Antonio E. Amílcar Cabral: Documentário (textos políticos e culturais). Lisboa: ed. Cotovia, Ltda, 2008.

FRANCO, Paulo Fernando Campbell. Amílcar Cabral: a palavra falada e a palavra vivida. 2009. Dissertação (Mestrado em História) - Universidade de São Paulo, São Paulo, 2009.

GOMES, Patrícia Godinho. Os fundamentos de uma nova sociedade: O P.A.I.G.C. e a luta armada na Guiné-Bissau (1963-1973): organização do Estado e relações internacionais. Torino: L'Harmattan Itália, 2010.

HAMPATÉ BÂ, Amaduo. A tradição viva. In KI-ZERBO, Joseph (org.) História Geral da África: metodologia e Pré-história da África. v. 1. Brasília: UNESCO, 2010. p. 167-212.

KOHL, Christoph. Construindo a não na África pós-colonial: o exemplo de Guiné-Bissau. Cadernos de Estudos Africanos, [s.l.], n. 20, p. 39-71, 2011.

LEMOS, Mário Matos. Os portugueses na Guiné-Bissau: apontamento para uma síntese. Lisboa: Ed. Crédito Predial Português, 1996.

LOPES, Carlos (org.). Desafios contemporâneos da África, o legado de Amílcar Cabral. São Paulo: Ed. UNESP, 2011.

LOPES, Carlos. Kaabunké: espaço, território, e poder na Guiné-Bissau, Gâmbia e Cassamance Pré-Coloniais. Lisboa: CNCDP, 1999.

M 'BOKOLO, Elikia. África negra: história e civilização. Salvador: EDUFBA; São Paulo: Casa das Áfricas, 2009. Tomo I.

MATEUS, Dalila C. A Luta pela independência: a formação das elites fundadoras da FRELIMO, MPLA e PAIGC. Lisboa: Inquérito 1999.

MENDY, Peter Karibe. Cabral na Guiné-Bissau colonial: contexto, desafios e conquistas. In: CABRAL NO CRUZAMENTO DE ÉPOCAS. Praia: Alfa Comunicações: 2005. p. 757-777.

MINISTÉRIO DA ECONOMIA, DO PLANO E DA INTEGRAÇÃO REGIONAL. Instituto Nacional de Estatística. Terceiro recenseamento geral da população e habitação. Bissau: O Ministério, 2009.

MONTEIRO, Artemisa O. Candé. Guiné portuguesa versus Guiné-Bissau: a luta da libertação nacional e o projeto de construção do estado guineense. [S.l.:S.n.], 2017. 
PARTIDO AFRICANO PARA A INDEPENDÊNCIA DA GUINÉ E CABO-VERDE.

Estatutos do Partido. [S.l.:S.n.], 1974.

PARTIDO AFRICANO PARA A INDEPENDÊNCIA DA GUINÉ E CABO-VERDE. História e estatutos de PAIGC. [S.l.:S.n., 20--]. Disponível em: www.paigc.org. Acesso em: 28 ago. 2021.

SEMEDO, Rui J. Conacri como espaço duplo: retaguarda de luta e de produção e reprodução de conflitos. Bissau: [s.n.], 2012.

VAMBE, Maurice Taonezvi; ZEGEYE, Abebe. Amílcar Cabral e as vicissitudes da literatura africana. São Paulo: Ed. Unesp, 2012. p. 35-68.

WICK, Alexis. A nação no pensamento de Amílcar Cabral. In. CABRAL NO CRUZAMENTO DE ÉPOCAS. Praia: Alfa Comunicações: 2005. p. 353-384. 